\title{
A Meta-Analysis of the Distinction between Reactive and Proactive Aggression in Children and Adolescents
}

\author{
Hanneke Polman • Bram Orobio de Castro • \\ Willem Koops · Herman W. van Boxtel • \\ Welmoet W. Merk
}

Published online: 6 March 2007

(C) Springer Science+Business Media, LLC 2007

\begin{abstract}
The present meta-analytic review aimed to clarify divergent findings concerning the relation between reactive and proactive aggression in children and adolescents. Fifty-one studies with 17,965 participants were included in the analysis. A significant correlation between reactive and proactive aggression was found. The strength of this relation varied considerably between studies, from -.10 to .89 . Observational assessment and tilt/noise tasks were associated with smaller correlations than questionnaires. Within the large group of questionnaire studies, studies disentangling the form and function of aggression found lower correlations than studies that did not disentangle form and function. Among questionnaire studies, higher reliability was associated with larger correlations. Effect size did not depend on other study characteristics such as sample type, age, and informant type. It is concluded that reactive and proactive aggression are most clearly distinguished with behavioral observations and questionnaires that unravel form and functions of aggression.
\end{abstract}

Keywords Meta-analysis - Reactive aggression - Proactive aggression · Aggressive behavior · Subtypes of aggressive behavior

Many recent studies of children's aggressive behavior distinguish between reactive and proactive aggression. Dodge (1991) defined reactive aggression as a reaction to a presumed threat which is associated with anger, and proactive aggression as planned, instrumental and "cold-blooded" be-

H. Polman $(\bowtie) \cdot$ B. Orobio de Castro · W. Koops ·

H. W. van Boxtel · W. W. Merk

Developmental Psychology, Utrecht University, Heidelberglaan 1, Utrecht, 3508 TC, The Netherlands

e-mail: J.D.M.Polman@fss.uu.nl havior. An important reason to distinguish between reactive and proactive aggression is the potential for furthering our understanding of the origins of aggression (Dodge, 1991). Different theories on aggression seem appropriate to explain either reactive or proactive aspects of aggression (Dodge, Lochman, Harnish, Bates, \& Pettit, 1997) but not both of them simultaneously. Therefore, it seems of great importance to test whether the two forms of aggression can be distinguished reliably, so that their proposed distinct origins can be studied. Furthermore, it has been supposed thatgiven the suggested different origins of reactive and proactive aggression - it would be beneficial to develop specific intervention components for each of these different forms of aggression (McAdams III, 2002).

Theoretical explanations for reactive aggression are derived from the frustration-aggression model. This model holds that aggressive acts are the consequence of frustration. If goals are blocked as a result of internal or external factors, hostility and anger may be triggered. These increased negative emotions can increase the readiness to display aggression to defend oneself or to inflict harm on the source of frustration. The more important the blocked goal, the greater the frustration, and the greater the aggressive impulse (Dollard, Doob, Miller, Mowrer, \& Sears, 1939). Proactive aggression is seen as a product of social learning. According to the principles of social learning, aggressive behavior is learned through operant conditioning and through vicarious learning from models. Proactive aggression is considered acquired instrumental behavior, that is controlled by contingencies. This kind of aggression is believed to be driven by relatively positive outcome expectancies and selfefficacy for these aggressive behaviors (Bandura, 1973).

Considerable support for the validity of the distinction between reactive and proactive aggression exists (see also Card \& Little, 2006). The two forms of aggression appear to 
be related to theoretically relevant different precursors, correlates and prognoses (Vitaro, Brendgen, \& Barker, 2006). Reactively aggressive children and not proactively aggressive children demonstrate histories of physical abuse and early onset of problems (Dodge et al., 1997). Reactive aggression appears to be uniquely related with attention problems and adjustment problems in peer relations (Dodge \& Coie, 1987). Reactive and proactive aggression appear to be concurrently related with different social informationprocessing patterns. Reactively but not proactively aggressive children attribute hostile intent to peers more frequently than other children (Crick \& Dodge, 1996; Dodge \& Coie, 1987; Dodge, Price, Bachorowski, \& Newman, 1990; Orobio de Castro, Merk, Koops, Veerman, \& Bosch, 2005; Schwartz et al., 1998). In contrast, only proactively aggressive children display a processing pattern of anticipating relatively positive outcomes for aggression (Dodge et al., 1997). Reactive aggression is weakly associated with low self-perceived social competence, whereas proactive aggression is associated with overestimation of such competencies (Orobio de Castro, Brendgen, Van Boxtel, Vitaro, \& Schaepers, 2007). Delinquent behavior in adolescent males is uniquely predicted by proactive aggression during early adolescence (Vitaro, Gendreau, Tremblay, \& Oligny, 1998). Brendgen, Vitaro, Tremblay, \& Lavoie (2001) found that proactive aggression is a unique predictor of delinquency-related violence, whereas reactive aggression uniquely predicts later dating violence.

However, even though research has statistically demonstrated these differences in precursors, correlates and prognoses there is concern over the apparently high co-occurrence of the two kinds of aggression. It has been questioned whether the correlation between reactive and proactive aggression is in fact too high to be scientifically and clinically useful (Bushman \& Anderson, 2001; Poulin \& Boivin, 2000a; Waschbusch, Willoughby, \& Pelham, 1998). Indeed, high correlations of up to $r=.87$ have been reported (Camodeca, Goossens, Meerum Terwogt, \& Schuengel, 2002; Dodge et al., 1990). However, more strikingly, correlations vary considerably between studies, ranging from -.10 (Little, Jones, Henrich \& Hawley, 2003) to .87 (Camodeca et al., 2002).

Thus, notwithstanding the findings on specific correlates of reactive and proactive aggression, the evidence concerning the fundamental proposition that reactive and proactive aggression are sufficiently distinct to be of scientific and clinical relevance is hard to interpret. Moreover, the reasons for the divergent findings on the strength of this relation are as yet unclear.

The present meta-analytic review aimed to clarify the inconsistent findings concerning the relations between reactive and proactive aggression, and to explore which participant, conceptual, and methodological characteristics may account for differences between these correlations. By doing so, we aimed to clarify whether the distinction is viable, and if so, how it can be made most clearly.

\section{Participant characteristics}

A number of participant characteristics may be expected to moderate the strength of the relation between reactive and proactive aggression. An influential factor may be the sample type. The correlation between reactive and proactive aggression may be smaller in a highly aggressive group than in general population samples for several reasons. In highly aggressive samples, specific pathologies would in theory contribute to specific kinds of behavior problems (e.g. attention deficit hyperactivity disorder to reactive but not proactive aggression). Moreover, distributions in general population samples are positively skewed on reactive and proactive aggression as many non-aggressive children will have low scores on both reactive and proactive aggression-items. This will have an increasing effect on the correlation between reactive and proactive aggression, as correlations are based on concordances in scores.

A second participant characteristic that may explain differences in effect sizes is participant gender. Given established gender differences in the incidence and development of aggressive behavior, it also seems important to study gender differences in the relation between reactive and proactive aggression. In a study by Connor, Steingard, Anderson \& Melloni (2003) no gender differences in proactive or reactive aggression were found. However, other studies report higher rates of both proactive and reactive aggression for boys compared with girls (Lansford, Dodge, Bates, \& Pettit, 2002; Salmivalli \& Nieminen, 2002). Inconsistencies in the possible effect of gender on the relation between reactive and proactive aggression leads to the investigation of this participant characteristic.

Furthermore, effects may depend on the variation in age of participants. Reactive aggression appears earlier in life than proactive aggression (Dodge et al., 1997), and is more stable over time (Lansford et al., 2002). Some children behaving in a reactively aggressive manner may then discover that aggressive behavior can lead to positive outcomes (Merk, Orobio de Castro, Koops, \& Matthys, 2005). Such reinforcement of aggressive behavior may instigate the development of proactive aggression, leading to a higher correlation between the two kinds of aggression with increasing age. Therefore, we expected correlations between reactive and proactive aggression to be higher for older children.

\section{Conceptual characteristics}

In addition to participant characteristics, effect sizes may also be related to conceptual differences. Researchers adopt 
different definitions when making a distinction between both forms of aggression. The terms reactive and proactive aggression are used in many studies, whereas other studies use the seemingly roughly equivalent terms hostile and instrumental aggression. Hostile aggression appears to be the same construct as reactive aggression as it is initiated by insult or attack, and its function is primarily the injury of the person towards whom it is directed. However, in comparing proactive aggression and instrumental aggression, inconsistencies prevail. Proactive aggression can emphasize bullying and/or instrumental elements. Studies may have defined proactive aggression as instrumentally proactive, bullying proactive, or instrumentally and bullying proactive. Instrumental elements predominantly regard object acquisition, whereas bullying elements involves domination or intimidation of another person (Brown, Atkins, Osborne, \& Milnamow, 1996). It is investigated whether these conceptual differences are associated with different effect sizes.

Furthermore, some researchers have postulated the idea to disentangle the form from the function of aggressive behavior (Kupersmidt, Willoughby, \& Bryant, 1998; Little, Jones et al., 2003; Prinstein \& Cillessen, 2003). It has been proposed that reactive and proactive aggression should primarily be conceptualized as functions of or reasons for aggressive behaviors. Such functions may be distinct from the actual forms of the behaviors, such as hitting or gossiping. Functions of aggression can either be reactive or proactive of nature. Forms of aggression identified in the literature include direct, physical, verbal, material, relational, indirect, and social aggression. Most measures of reactive and proactive aggression to date include undifferentiated mixtures of form and function of aggression (Little, Jones et al., 2003). For instance, a proactive item in the most widely used measure TRI is "uses physical force to dominate," and a reactive item "when teased, strikes back" (Dodge \& Coie, 1987). Both items demonstrate an overt (physical) form, however, the first item concerns a proactive function, whereas the second item deals with a reactive function. Emphasizing on forms of behavior, may result in erroroneously high correlations between reactive and proactive aggression as different functions may not be distinguished by respondents if they tend to focus on the form (which is the same in both items). These high correlations can, then, probably be ascribed to the established correlations between forms of aggression in the .54 to .77 range (Crick, 1996; Crick, Casas, \& Mosher, 1997; Crick \& Grotpeter, 1995; Grotpeter \& Crick, 1996), In the above example, a respondent might thereby rate a child high in both reactive and proactive aggression because it often hits others, not because it does so with both functions.

If so, questionnaire studies involving a distinction between form and function and thereby controlling for the overriding forms of aggressive behavior should report lower correlations between reactive and proactive aggression than studies where this distinction was not made (Little, Jones et al., 2003).

\section{Methodological characteristics}

Effect sizes may also be related to methodological characteristics of studies. Different informants concerning aggression may be associated with different effect sizes. Cross-informant correlations for aggression generally show little agreement (Achenbach, McConaughy, \& Howell, 1987; Little, Brauner, Jones, Nock, \& Hawley, 2003; Pakaslahti \& Keltikangas-Jaervinen, 2000). Due to different settings in which aggressive behavior is evaluated, differences between informants in the assessment of reactive and proactive aggression may exist. Children may demonstrate different levels of both forms of aggression in a home setting in comparison with a school setting. It is, therefore, possible that teacher and peer evaluations of reactive and proactive aggression lead to other correlations than parent evaluations. Due to high levels of exposure to, and involvement with the behavior of their aggressive age mates, peers may be better at differentiating between reactive and proactive aggression than parents and teachers. This would result in a smaller correlation between reactive and proactive aggression in peer reports. Concerning self-reports, moderate correlations between reactive and proactive aggression are to be expected. On the one hand, participants may be considered better informed of the distinct motivations for their aggressive behaviors than others. On the other hand, it is questionable whether participants are accurate in their evaluations of their own aggressive behavior as it has been found that aggressive boys systematically underperceive their own aggressiveness (Lochman \& Dodge, 1998).

Differences in type of aggression measure used may also be related to effect sizes. Most studies have assessed reactive and proactive aggression with questionnaires. Others have used observations of aggressive behavior. Observational studies use a focal-child, event-based system to assess reactive and proactive aggression in the classroom or during free play. Proactive and reactive aggression (or instrumental and hostile aggression) have also been assessed with a competitive game. This task required participants to accumulate points in a pinball game in competition with an unknown peer who was presumed to be playing the game in and adjacent room (Atkins \& Stoff, 1993). In this so-called 'tilt-noise' task pressing a tilt button, which allegedly interferes with the opponent's progress, is presumed to be a measure of instrumental/proactive aggression because of the possible gain obtained by blocking the opponent's game. Pressing a noise button, which allegedly causes the opponent to hear an aversive noise, is presumed to be a measure of hostile/reactive aggression, because of the lack of advantage afforded to the subject by this response (Atkins \& Stoff, 1993). We expected 
questionnaires to be associated with higher correlations between reactive and proactive aggression than observational studies and tilt/noise tasks, because questionnaires call for general impressions of a person's behavior, whereas observations and tilt-noise tasks call for direct evaluation of distinct behaviors. Also, when filling out a questionnaire, people may be inclined to answer each question in line with their general impression of the participant (halo-effect), rather than in response to the specific question being posed (Saal, Downey, \& Lahey, 1980. In case of aggression this would result in generally high or low scores for all aggression-related items, regardless the reactive or proactive formulation of specific items.

Observational studies, on the other hand, provide judgments of discrete behaviors by independent trained observers and may thereby lead to lower correlations between reactive and proactive aggression. Moreover, observation of a limited number of interactions in a single context may have an a priori higher probability for a specific behavior to occur that fits that context, than the general impressions obtained by questionnaires that are presumably based on a variety of interactions in multiple contexts.

Within the group of studies using questionnaires, we distinguished by questionnaire type used. Questionnaire type most often concerned The Teacher Rating Instrument (TRI) developed by Dodge and Coie (1987) and Brown's revised teacher rating scale for reactive and proactive aggression (Brown et al., 1996). Within this group, we further investigated a possible relation between number of items, reliability, and effect size. Questionnaires with more items were expected to demonstrate higher levels of reliability. Low reliability results in lower correlations, as the large measurement error of unreliable measures contributes to within group variance (Orwin, 1994).

In sum, we aimed to study the relation between reactive and proactive aggression, and to test whether the abovementioned participant, conceptual, and method characteristics explain the considerable differences between studies in the strength of this relation. Participant characteristics expected to explain differences in effect sizes were sample type, gender, and age. Conceptual characteristics thought to explain differences in effect sizes were definition, and disentanglement of form and function. Methodological characteristics of interest were informants, aggression measure, questionnaire type, number of items, and reliability.

\section{Method}

Study selection

We aimed to include all empirical studies involving the relation between reactive and proactive aggression in children and adolescents conducted between January 1950 and July 2003. Reactive aggression was defined as aggression that occurs as an angry defensive response to a presumed threat and proactive aggression as planned cold-blooded behavior in order to take possession of things or to dominate or intimidate. (Dodge, 1991).

Four sources were used to identify potentially eligible studies. First, a large set of studies was retrieved by searches in online data bases such as PSYCINFO (http://www. psycinfo.com), Web of Science (http://www.isinet.com), ERIC (http://www.ericnet.com), and Dissertation Abstracts International (http://wwwlib.umi.com/dxweb/gateway). The keywords used in the search were "reactive aggression" and "proactive aggression," and additionally "hostile aggression" and "instrumental aggression." Second, bibliographies of retrieved studies were examined for possible related eligible studies. Third, to include a representative sample of unpublished papers in the meta-analysis, the program book of the International Society for Research in Aggression conference in Montreal, Canada (2002) was searched. Fourth, researchers in the field were contacted by the authors in order to find other relevant studies. This exhaustive search resulted in 124 titles. In spite of extended searches and attempts to contact the authors, we were unable to retrieve 8 of these studies: 3 journal articles, and 5 unpublished papers. Consequently, 116 studies (94\%) were checked for eligibility in the meta-analysis.

Several selection criteria were used to include studies in the meta-analysis. The study should, (a) report quantative data on both reactive and proactive aggression, (b) concern children or adolescents, (c) not regard reactive and proactive aggression in a specific context (for instance, studies dealing specifically with sportsmen), (d) not make use of data from other studies included in the meta-analysis (to ensure independence of effect sizes). (e) provide sufficient information on the investigated participant, conceptual, and methodological characteristics, and (f) report a correlation between reactive and proactive aggression or provide sufficient statistics to permit calculation of this correlation. ${ }^{1}$ If the correlation between reactive and proactive aggression was not presented, the first or second author was contacted.

Of the 116 studies checked for eligibility, 45 studies met the criteria for inclusion. This selection consisted of 33

\footnotetext{
${ }^{1}$ In case of a classification into groups of aggressive subtypes (reactive aggressive, proactive aggressive, pervasively aggressive, nonaggressive), it is possible to estimate a correlation. Such estimates may, however, be inaccurate (Guilford, 1995 in Lipsey \& Wilson, 2001) Analysis of five studies reporting both a correlation between raw scores and group classification (Camodeca et al., 2002; Day et al., 1992; Dodge \& Coie, 1987; Salmivalli \& Nieminen, 2002; Steffens, 1999), indeed revealed a mean difference of .23 between actual correlations and estimates based on group sizes. Because of the magnitude of this bias, we decided to exclude studies that only reported on group classifications.
} 
(73\%) published journal articles, and 12 (27\%) unpublished studies. The unpublished studies were six dissertations, five conference papers, and one master thesis. There was a marginally significant difference in effect size between published $(r=.60)$ and unpublished studies $(r=$ .73), $Q(I)=3.80, p=.05$. This effect may be due to publication bias favoring studies reporting lower correlations. This does, however, seem unlikely, because assessing the correlation between reactive and proactive aggression was rarely the main aim of studies, and will therefore not have been a major criterion for publication (see also discussion section). It seems more likely that the effect is best explained by differences in study characteristics between published and unpublished studies.

Several studies included multiple independent effect sizes, resulting in 51 effect sizes with a total of 17,965 participants included in the meta-analysis. A list of these studies and their main characteristics with details of effect-size calculation is available from the authors on request, as is a motivated list of excluded studies.

\section{Coding of study characteristics}

All eligible reports were coded by the first author using a detailed coding scheme. Eleven studies were also coded by an independent research associate and the second author. Cohen's kappa was computed for the coded nominal variables included in the meta-analysis. Excellent between rater reliability coefficients were obtained. Kappa's were 1 for sample type, definition, disentanglement of form and function, informants, aggression measure, and questionnaire type. Intraclass correlations were 1 for gender (percentage of boys in sample), number of items, sample size, and effect size and .99 for reliability.

\section{Participant characteristics}

Concerning sample type a distinction was made between studies including highly aggressive samples and studies including only general population samples or children with other problems (that did not necessarily include aggressive behavior). Highly aggressive samples consisted of nonreferred samples selected on highly aggressive behavior (e.g. one $S D$ above the mean), or samples referred to any type of intervention (special education, psychiatric care, prison, etc.) for aggressive, disruptive, or antisocial behavior problems. Studies with general population samples included a single sample from the general nonreferred population and studied the relation between reactive and proactive aggression as a correlation over this entire sample.

Percentage of boys in each sample was coded as a measure of gender and mean age of participants was coded directly or estimated from reported school grades. In some instances only the age range was reported. Mean ages were then estimated by averaging the minimum and maximum reported. There were also studies that did not report on ages, but on grades of participants. Grades were transformed to ages by adding five years to the reported grade.

\section{Conceptual characteristics}

A distinction was made between definitions as "reactive/ hostile vs. instrumental proactive," "reactive/hostile vs. bullying proactive" and "reactive/hostile vs. instrumental and bullying proactive." Also, it was coded whether questionnaire studies did or did not disentangle form and function of aggressive behavior. Disentanglement of form and function only concerned studies in which the form of aggression was unraveled from its function, either statistically or in assessment.

\section{Methodological characteristics}

Six different types of informants were distinguished: teacher, parent, peer, self, staff member, and researcher. Regarding aggression measure it was coded whether studies used questionnaires, behavioral observations, or tilt/noise tasks. For questionnaire studies, questionnaire type was coded. One of the questionnaire types was the Teacher Rating Instrument developed by Dodge and Coie (1987). Another frequently used measure was the revised teacher rating scale developed by Brown et al. (1996). Other questionnaires included nomination procedures.

For questionnaires, the number of items was coded. In case of factor analysis, the number of items coded was the number of items included in the reactive and proactive aggression scales after factor analysis had been conducted. For questionnaires Cronbach's alpha mean reliability for reactive and proactive aggression was noted, if available. If studies reported on minimum and maximum alpha values for both reactive and proactive aggression, the lowest alpha was included.

\section{Effect size calculations}

All effect sizes were transformed to Fisher Zs. The distribution of coefficients sampled from a population is skewed, which results in a small bias when comparing correlation coefficients from different studies (Field, 1999). Fisher Zs measure corrects for the nonlinearity of the correlation coefficient at extreme values. All meta-analytic calculations were performed on Fisher $Z \mathrm{~s}$ weighed by the inverse variance. According to Lipsey and Wilson (2001) the inverse variance weight is $n-3$ for effect sizes based on the product-moment 
correlation. To facilitate interpretation, Fisher $Z$ scores were transformed back to correlations for presentation in this text.

\section{Data analyses}

Three issues were addressed. First, we tested whether the mean effect size was significantly larger than zero. Second, tests for heterogeneity were performed in order to study the distribution of effect sizes. If a set of studies is heterogeneous, the variation in effect sizes is so large that it is improbable that these effect sizes represent one single population effect size. For heterogeneous studies, a single estimate of a mean effect size is not very relevant, as a heterogeneous group of effect sizes does not represent a single population effect size. A mixed effects model should then be assumed which implies that a portion of the excess variability is systematic and can be statistically modeled, and that differences among the effect sizes have some source other than subject-level sampling error, perhaps differences associated with different study characteristics. Another portion of the variance may be random and cannot be modeled (Lipsey \& Wilson, 2001).
Third, we consequently tested whether the excess variability could be explained by associations with the a priori hypothesized moderator variables. These moderator tests, when successful should result in homogeneous subgroups and differences in mean correlations between these groups (Allen, D’Alessio, \& Brezgel, 1995).

For studies reporting multiple dependent effect sizes, only the most informative effect size was selected. For instance, Schwartz (1994) reported on teacher and peer assessment of reactive and proactive aggression. Because of the scarcity of studies involving peer informants, only the correlation between reactive and proactive aggression based on information provided by peers was included in the meta-analysis.

\section{Results}

Distribution of study characteristics

Frequency distributions of study characteristics for all studies are presented in the leftmost columns of Table 1. For the sake of clarity, in Table 1 the continuous variables gender

Table 1 Moderators of effect size by aggression measure

\begin{tabular}{|c|c|c|c|c|c|c|c|c|c|c|c|c|}
\hline \multirow[b]{3}{*}{ Study characteristic } & \multicolumn{12}{|c|}{ Aggression measure } \\
\hline & \multicolumn{3}{|c|}{ All studies } & \multicolumn{3}{|c|}{ Questionnaire } & \multicolumn{3}{|c|}{ Observation } & \multicolumn{3}{|c|}{ Tilt/Noise } \\
\hline & $\bar{K}$ & $N$ & $r$ & $\bar{K}$ & $N$ & $r$ & $\bar{K}$ & $N$ & $r$ & $\bar{K}$ & $N$ & $r$ \\
\hline \multicolumn{13}{|l|}{ Sample type } \\
\hline General population & 39 & 15,885 & .63 & 29 & 15,034 & .71 & 7 & 574 & .20 & 3 & 277 & .43 \\
\hline Highly aggressive group included & 12 & 2,080 & .65 & 11 & 2,000 & .66 & & & & 1 & 80 & .53 \\
\hline \multicolumn{13}{|l|}{ Gender } \\
\hline Only boys & 21 & 2,956 & .61 & 14 & 2,519 & .71 & 4 & 241 & .25 & 3 & 196 & .43 \\
\hline Both boys and girls & 29 & 12,459 & .65 & 25 & 11,965 & .69 & 3 & 333 & .18 & 1 & 161 & .51 \\
\hline \multicolumn{13}{|l|}{ Age group } \\
\hline $3-6$ & 8 & 1,767 & .44 & 3 & 1,333 & .71 & 5 & 434 & .19 & & & \\
\hline $6-9$ & 11 & 1,997 & .67 & 8 & 1,696 & .74 & 2 & 140 & .30 & 1 & 161 & .51 \\
\hline $9-12$ & 21 & 8,541 & .70 & 18 & 8,345 & .74 & & & & 3 & 196 & .43 \\
\hline$>12$ & 11 & 5,660 & .58 & 11 & 5,660 & .58 & & & & & & \\
\hline \multicolumn{13}{|l|}{ Definition } \\
\hline Reactive vs. instrumental proactive & 7 & 3,174 & .36 & 2 & 2,785 & .34 & 1 & 32 & -.06 & 4 & 357 & .45 \\
\hline Reactive vs. bullying proactive & 24 & 11,655 & .74 & 24 & 11,655 & .74 & & & & & & \\
\hline Reactive vs. instrumental \& bullying & 20 & 3,136 & .57 & 14 & 2,594 & .66 & 6 & 542 & .27 & & & \\
\hline \multicolumn{13}{|l|}{ Disentanglement form/function } \\
\hline Disentangling & 3 & 2,527 & .42 & 3 & 2,527 & .42 & & & & & & \\
\hline Non-disentangling & 48 & 15,438 & .65 & 37 & 14,507 & .72 & 7 & 574 & .20 & 4 & 357 & .45 \\
\hline \multicolumn{13}{|l|}{ Informant } \\
\hline Teacher & 23 & 7,578 & .74 & 23 & 7,578 & .74 & & & & & & \\
\hline Parent & 5 & 1,147 & .68 & 5 & 1,147 & .68 & & & & & & \\
\hline Peer & 3 & 1,739 & .67 & 3 & 1,739 & .67 & & & & & & \\
\hline Self & 4 & 5,941 & .51 & 4 & 5,941 & .51 & & & & & & \\
\hline Staff member & 5 & 629 & .67 & 5 & 629 & .67 & & & & & & \\
\hline Researcher & 11 & 931 & .30 & & & & 7 & 574 & .20 & 4 & 357 & .45 \\
\hline Total & 51 & 17,965 & .64 & 40 & 17,034 & .70 & 7 & 574 & .20 & 4 & 357 & .45 \\
\hline
\end{tabular}

Note. Results only concern categorical variables, $K=$ number of studies; $N=$ number of participants; $r=$ transformation of mean Fisher $Z$ weighed by the inverse variance weight. 
and age were presented as categorical variables. However, in analyses they were treated as continuous variables.

\section{Overall effect size}

The overall mean correlation between reactive and proactive aggression was highly significant, $Z=14.57, p<.001$, with a mean effect size of $r=.64$. However, the expected divergence in correlations was indeed considerable, ranging from $r=-.10$ to $r=.89$. The effect size distribution was not significantly heterogeneous, $Q(50)=47.78, p=$ .56. However, the small number of effect sizes resulted in a $Q$ test with relatively little power for rejecting the null hypothesis of homogeneity (Wilson \& Lipsey, 2000). The large variability in effect sizes warranted further analyses of effect size moderators.

\section{Moderator analyses}

To test whether variance in effect size could be explained by the hypothesized participant, conceptual, and methodological characteristics of studies, each moderator effect was first tested individually. Mean effect sizes by moderators are listed in the leftmost columns of Table 1. Effect sizes were moderated by definition, $Q(2)=22.35, p<.001$, informant, $Q(5)=25.36, p<.001$ and aggression measure, $Q(2)=$ $19.63, p<.001$.

Then, the relative contribution of each moderator to explained variance was tested with a mixed effects multiple regression analyses with all moderators entered simultane-
Table 2 Multiple regression of moderators among all studies

\begin{tabular}{lrrr}
\hline Study characteristic & B & SE B & \multicolumn{1}{c}{ Beta } \\
\hline Sample type & -0.04 & 0.13 & -0.05 \\
Gender & 0.00 & 0.00 & 0.10 \\
Age & -0.01 & 0.02 & -0.10 \\
$\begin{array}{l}\text { Definition (dummy coded for } \\
\text { instrumental) }\end{array}$ & -0.21 & 0.11 & -0.29 \\
$\begin{array}{l}\text { Informant (dummy coded for } \\
\text { teacher) }\end{array}$ & 0.15 & 0.12 & 0.20 \\
$\begin{array}{l}\text { Aggression Measure (dummy } \\
\text { coded for questionnaire) }\end{array}$ & 0.41 & 0.19 & $0.46^{*}$ \\
\hline
\end{tabular}

Note. Model: $Q(6)=29.06, p<.001$; Residual: $Q(43)=28.15$, $p=.96 ; R^{2}=.51$.

${ }^{*} p<.05$.

ously. As presented in Table 2, aggression measure $(\beta=$ 0.46) explained most variance in effect sizes, $Z=2,13$, $p=.03$. As can been seen in Fig. 1, questionnaire studies found higher correlations $(r=.70)$ than behavioral observations $(r=.20)$ and tilt/noise tasks $(r=.45)$. Results of the homogeneity tests indicate homogenous groups of studies involving questionnaires, $Q(39)=25.21, p=.96$, behavioral observations, $Q(6)=2.36, p=.89$, and tilt/noise tasks, $Q(3)=0.58, p=.90$.

As aggression measure explained most of the variance in effect sizes and because of the distinct characteristics of studies with different measurement types, further moderator analyses were conducted within each measurement type separately. Effect sizes and study characteristics by aggression measure are shown in the middle to rightmost columns of
Fig. 1 Effect size by aggression measure

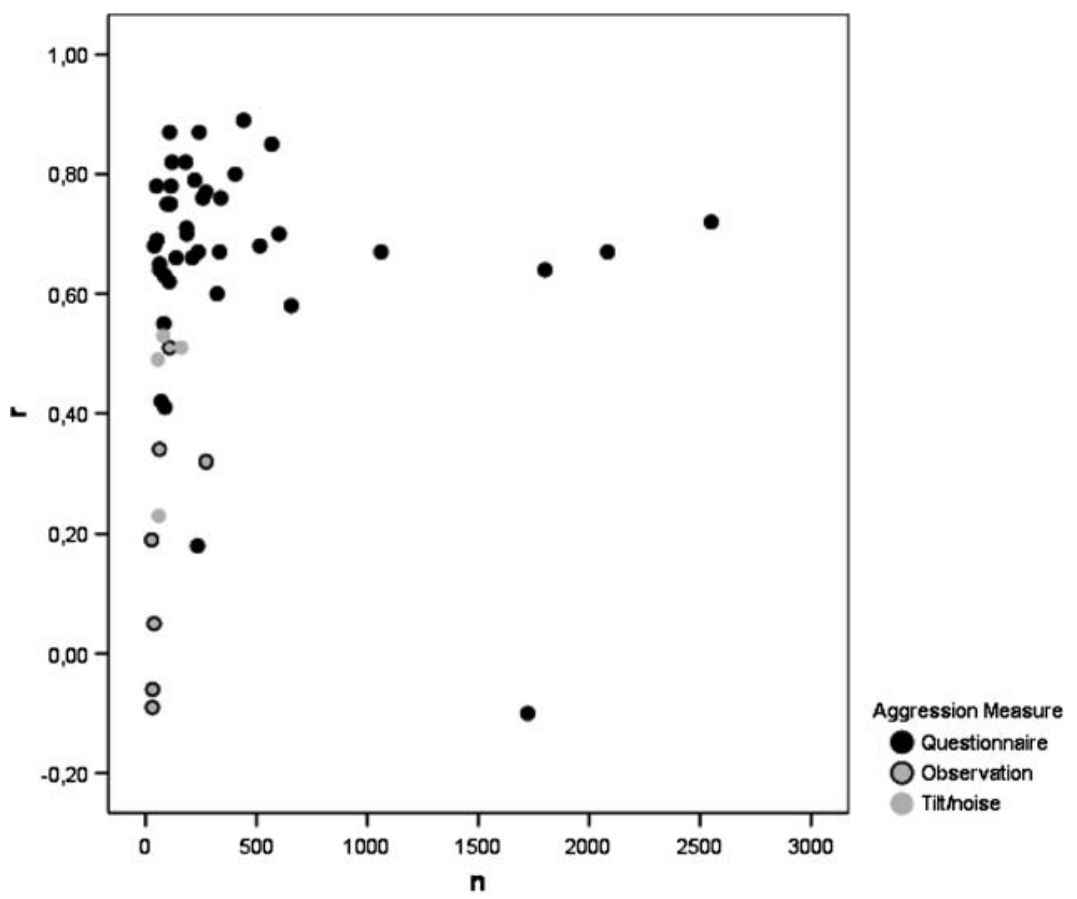


Fig. 2 Graphical display of moderator analyses

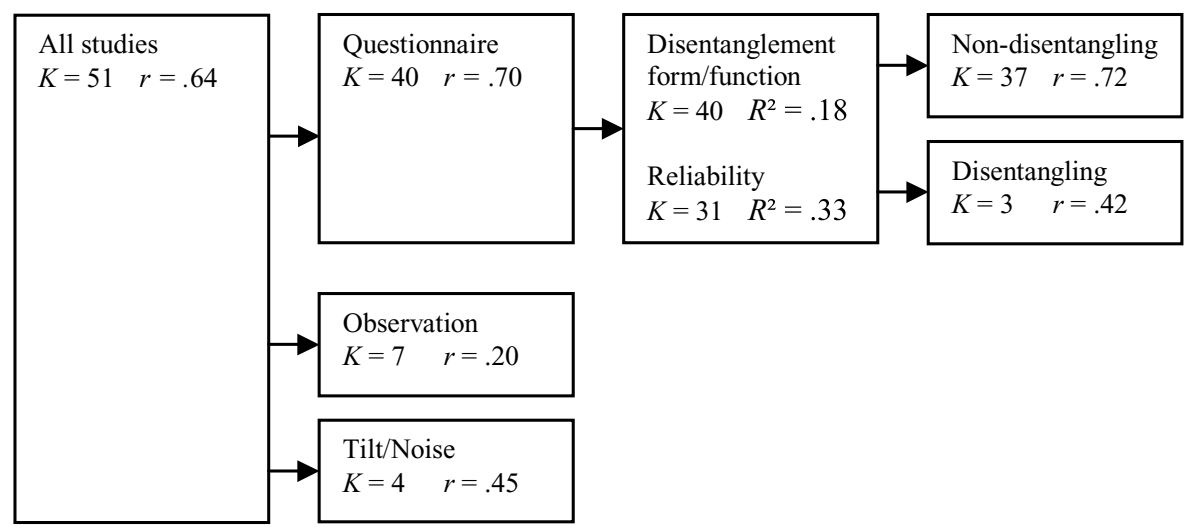

Table 1. The order of further moderator analyses is displayed graphically in Fig. 2.

\section{Moderators among questionnaire studies}

For several reasons, further moderator effects could only be analyzed further among the 40 studies using questionnaires. First, there were only seven observational studies and four tilt/noise tasks included in the meta-analysis, so analyses of moderator effects for observational studies and tilt/noise tasks would have involved (nearly) empty cells for rare combinations of characteristics. Second, some moderator variables only concerned questionnaires (disentanglement of form and function, number of items, reliability), but not behavioral observations or tilt/noise tasks. Third, within observational studies and tilt/noise studies there was no variance in informants.

Among the 40 questionnaire studies, it was investigated whether participant characteristics sample type, gender, and age, conceptual characteristic disentanglement of form and function, and methodological characteristics informants (dummy coded for teacher), and questionnaire type (dummy coded for TRI), moderated effect size significantly. ${ }^{2}$ Because of the strong relation between definition on the one hand and aggression measure and questionnaire type on the other hand, the variable definition was omitted from analyses. As presented in Table 3, a weighted multiple regression showed that the variables included in the model accounted for a significant proportion of the observed variability in

\footnotetext{
${ }^{2}$ Due to multiple unreported methodological characteristics, number of items $(K=37)$ and reliability $(K=31)$ could only be analyzed with separate weighted regression analyses. Number of items was analyzed without a study with an extreme value on this variable (number of items $=72$, Kupersmidt, Willoughby, \& Bryant, 1998). Number of items was not related to effect size, $R^{2}=.05, p=.16$. Reliability was significantly related to effect size, $R^{2}=.33, p=.01$, with larger correlations for measures with high reliabilities. Note, however, that reliability was confounded with questionnaire type and disentanglement of form and function, as the highest reliabilities were found for the nondisentangling TRI.
}

the effect size estimates, $R^{2}=.31, p=.04$, and left a nonsignificant residual. However, only the variable disentanglement of form and function $(\beta=-.39)$ individually made a significant independent contribution to the prediction of effect size among these studies, $Z=-2.36, p=.02$. As predicted, disentangling questionnaires were associated with lower correlations $(r=.42)$ between reactive and proactive aggression than non-disentangling questionnaires $(r=.72)$. These significant findings indicated the importance of a more parsimonious model. A reduced multiple regression model including only the individually significant predictor disentanglement of form and function $(\beta=-.42)$ accounted for a significant proportion of the observed variability in effect size estimates, $R^{2}=.18, p=.01$. The residual was not significant, indicating that the variance unaccounted for after fitting the regression model was not greater than to be expected from sampling error (Wilson \& Lipsey, 2000).

In sum, variance in the strength of the correlation between reactive and proactive aggression was best explained by aggression measure and disentanglement of form and function. These moderator effects are depicted together in Fig. 3.

\section{Discussion}

A meta-analytic review was conducted to test whether the considerable differences between studies in the strength of

Table 3 Multiple regression of moderators among questionnaire studies

\begin{tabular}{lrrr}
\hline Study characteristic & B & SE B & Beta \\
\hline Sample type & -0.11 & 0.12 & -0.17 \\
Gender & 0.00 & 0.00 & 0.10 \\
Age & -0.03 & 0.02 & -0.24 \\
Disentanglement form function & -0.42 & 0.18 & $-0.39^{*}$ \\
Informant (dummy coded for teacher) & 0.07 & 0.11 & 0.11 \\
Questionnaire type (dummy coded for TRI) & 0.00 & 0.10 & 0.01 \\
\hline
\end{tabular}

Note. Model: $Q(6)=13.13, p=.04$; Residual: $Q(32)=28.71, p=$ $.63 ; R^{2}=.31$.

${ }^{*} p<.05$. 
Fig. 3 Effect sizes by measure type and disentanglement of form and function. For each cluster the dark band shows the median, the bar indicates the quartile range, and the lines connect the extreme values. The circle is an outlier

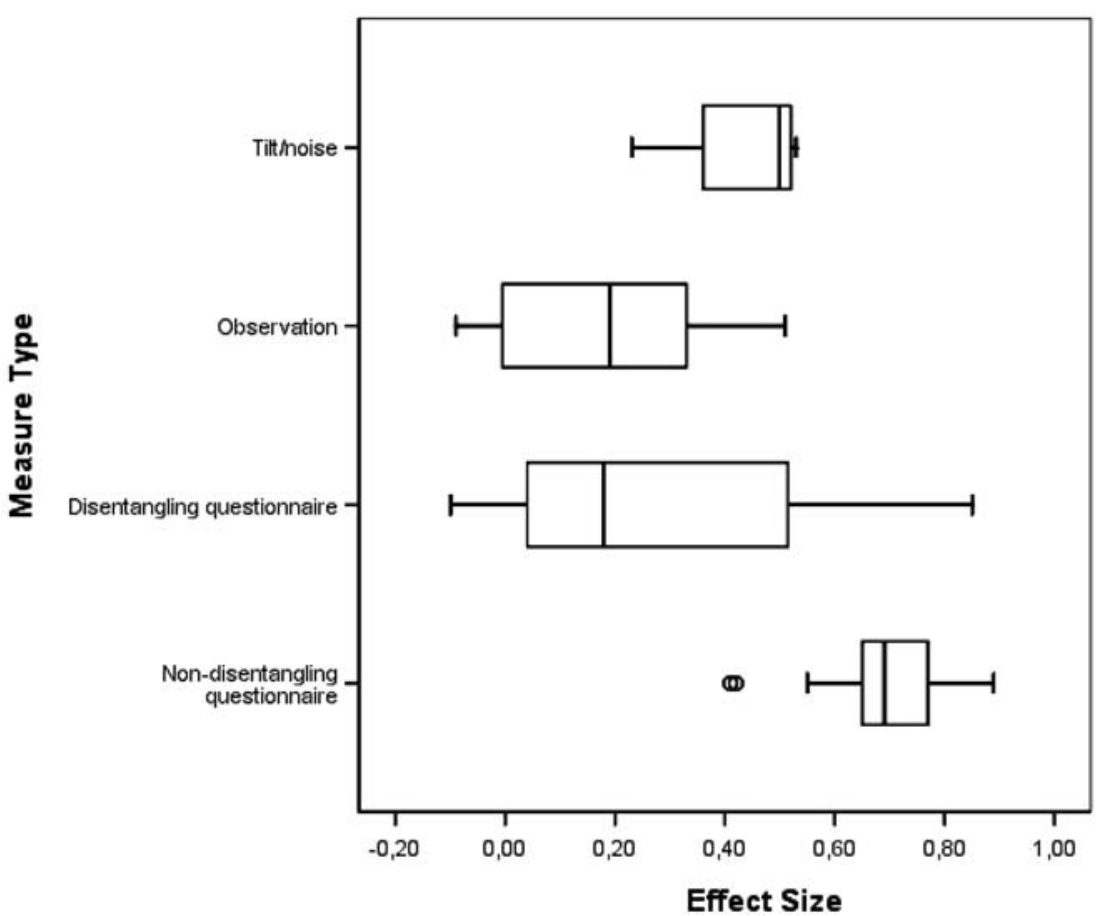

the relation between reactive and proactive aggression could be explained by participant, conceptual, and methodological characteristics of the studies. Aggression measure was the strongest moderator of the correlation between reactive and proactive aggression. Observation, assessment with tilt/noise tasks, and questionnaires disentangling forms and functions of aggression provided lower correlations between reactive and proactive aggression than assessment with nondisentangling questionnaires. Among questionnaire studies, higher reliability was associated with a higher correlation between reactive and proactive aggression. Reactive and proactive aggression thus are clearly distinct phenomena, that can be distinguished most strongly with behavioral observations or questionnaires that disentangle form and function, but less so with commonly used questionnaires that do not make such a disentanglement.

\section{Aggression measure}

\section{Observational studies}

The small group of observational studies demonstrate the ability of independent observers to distinguish between instances of reactive and proactive aggression. However, behavioral observation studies in the meta-analysis have focused on children no older than nine years old. Whether observers can discriminate between reactive and proactive aggression in, for instance, adolescents is uncertain. It should also be noted that the seven effect sizes for behavioral obser- vations were taken from three studies from which multiple independent effect sizes were taken. Therefore, some dependence exists due to utilization of the same category system and observers. However, the magnitude of the difference found between observations and questionnaires is so large that these dependencies are unlikely to account for the entire difference. In this regard, it is interesting that in one study a direct comparison was made between questionnaire and direct observations of the same participants (Price \& Dodge, 1989). As in our meta-analytic comparisons, teacher questionnaires revealed a far stronger correlation $(r=.83)$ than the correlation obtained through behavioral observations $(r=.05)$. These findings offer considerable support for the use of behavioral observations in studies on reactive and proactive aggression.

It may seem paradoxical that observations would permit distinguishing between functions of aggression, because functions of behavior may not appear directly observable. However, the proposed functions of reactive and proactive aggression are by no means deeply hidden intrapersonal motivations or drives, only accessible through introspection. On the contrary, the functions of responding aggressively to provocation or conducting reinforced aggressive behavior may be inferred from antecedents to the behavior (such as provocation or potential gain), characteristics of the behavior itself (such as anger, speed) and consequences (such as gain, dominance). Thus, observations may be well suited to conduct function analyses following the time-honoured $\mathrm{ABC}$ (Antecedent, Behavior, Consequences) pattern. Additional 
assessment of cognitive and emotional processes may enrich such function analyses, but does not seem crucial to understanding functions of behavior.

\section{Tilt noise}

Use of tilt/noise tasks was associated with equally low correlations as observations. However, in contrast with the clear validity of observational studies, the validity of tilt/noise task designs for the assessment of reactive and proactive aggression is questionable. In these laboratory tasks, participants are instructed that they may use tilt or noise as part of a game. Being thus instructed, using tilt and noise may be seen as legitimate within the rules of the game, and therefore as relatively harmless. Whether such permitted behaviors in the context of a game are indicative of an actual intention to harm others, and how they are related to actual aggressive behavior in real-life interactions with peers is as yet unclear.

\section{Questionnaire studies}

The large correlation in questionnaire studies suggest it may be problematic for informants to differentiate between both kinds of aggression by means of a questionnaire, even though the distinction can in principal be made. Even a questionnaire study explicitly informing teachers of the distinction between reactive and proactive aggression, revealed a high correlation of .82 (Poulin \& Boivin, 2000a).

A fundamental difference between questionnaire studies on the one hand and observational and tilt/noise tasks on the other hand is their unit of analysis. Questionnaires are used to evaluate persons, whereas observations and tilt/noise tasks evaluate individual behaviors or behavior sequences. This fundamental difference in conceptualization of reactive and proactive aggression as either individual behaviors or person characteristics has-to our knowledge-rarely been addressed explicitly. The definitions of reactive and proactive aggression clearly refer to specific behaviors, yet research has focused primarily on reactive and proactive aggression as distinct behavioral styles that distinguish between (groups of) children and their development. It is, however, quite possible that reactive and proactive aggression are very distinct behaviors, yet that they do often co-occur within individuals.

The high correlations found with most questionnaires may also result from characteristics of the specific questionnaires used in most research reviewed here. Most studies administered the TRI (Dodge \& Coie, 1987). High correlations between reactive and proactive aggression found with these specific questionnaires may partly be attributable to high item loadings on both factors (double loading). Analyses of factor loadings revealed that one out of three reactive items and two out of three proactive items from the TRI have double loadings ( $>.40$, Dodge \& Coie, 1987, studies I and II). One may wonder whether these double loadings and strong correlations are indicative of a more fundamental issue that would compromise the construction of all such questionnaires. Interestingly, these questionnaires did not disentangle form and function of aggression.

\section{Disentangling form and function}

Differences in correlations between reactive and proactive aggression are related with the disentanglement of the form and function of aggression. Questionnaires that disentangled forms and functions of aggression, were associated with much lower correlations than studies that did not make such a disentanglement. Focusing on the functions of aggressive behavior is instructive due to its informative value about why individuals engage in aggressive behavior (Little, Brauner et al., 2003). Definitions of proactive and reactive aggression emphasize the reasons why people behave aggressively. Tentative distinct theoretical explanations for reactive and proactive aggression also focus on the functions of aggression rather than on the forms it takes (e.g. Dodge et al., 1997), as reactive aggression is considered a product of frustration and proactive aggression is considered an acquired instrumental behavior which is controlled by its reinforcements or vicarious learning (Dodge et al., 1997). Also, coding systems used in observational studies (which revealed low correlations) have an emphasis on the functions of aggression (Boivin et al. 1995, Hegland \& Rix, 1990, Price \& Dodge, 1989). Similarly, the rationale for suggesting specific intervention components for reactive and proactive aggression is in the proposed different functions of these behavior rather than in different forms (Little, Brauner et al., 2003).

It is not yet quite clear how well informants are capable to distinguish between reactive and proactive functions of aggression, as there were only three studies included in the meta-analysis that disentangled function from form (Kupersmidt et al., 1998; Little, Jones et al., 2003; Prinstein \& Cillessen, 2003), with a great divergence in correlation $(-.10, .18$, and .85$)$. Thus, the extent to which functions are found to be independent dimensions seems to depend strongly on the way these functions were assessed. Examination of multiple approaches to disentangling reactive and proactive aggression functions is urgently called for.

To what extent subjective impressions of functions provided by different informants correspond to actual functions of the behaviors studied is not yet clear. Different approaches to disentangling form and function of aggression have been taken (Brendgen et al. 2006; Kupersmidt et al., 1998; Little, Jones et al., 2003; Ostrov \& Crick in press, Prinstein \& Cillessen, 2003). It may seem as if self-report is to be preferred in order te assess other people's cognitive and emotional states, seemingly needed to attribute functions to behaviors. It does, however, seem possible for observers to 
infer functions of aggressive behavior from antecedents, characteristics, and consequences related to specific behaviors, without self-reported introspective information. Also, it appears that introspection into one's own motives is not necessarily more valid than making inferences from observations (Nisbett \& DeCamp Wilson, 1977). It would be most informative to study this issue empirically by comparing evaluations of the functions of discrete aggressive behaviors made by different informants and self-reports.

Moderators among questionnaire studies

Among questionnaire studies, reliability made a contribution to the prediction of the relation between reactive and proactive aggression. Sample type, gender, age, informants, and number of items were not significantly associated with effect size. Surprisingly, general population samples were not found to reveal higher correlations between reactive and proactive aggression than highly aggressive groups. The failure to find a relationship between sample type and effect size may be ascribed to underrepresentation of purely problematic and purely referred samples. Studies including some sort of problematic group, often included a non-aggressive reference group as well. As correlations were only mentioned for the entire sample, these correlations may not represent the true relation between sample type and effect size. More studies directly comparing clinically aggressive and general population samples are needed to shed light on the relation between sample type and effect size.

Given established gender differences in the nature and development of aggressive behavior, it was remarkable that gender differences did not account for differences in the relation between reactive and proactive aggression. Although different precursors, correlates and prognoses may apply to aggressive behavior in boys and girls, the relation between reactive and proactive aggression seems to be equivalent. However, findings about the relation between gender and effect size should be interpreted cautiously, as girls were underrepresented in the analyzed studies.

Concerning age, we did not find the expected higher correlations between reactive and proactive aggression for older compared to younger children. In addition, individual studies reporting on independent age groups showed no differences in correlation between different age groups (Boivin et al., 1995; Price \& Dodge, 1989; Roland \& Idsøe, 2001). Taken together, it can be concluded that inconsistencies concerning the relation between age and the correlation between reactive and proactive aggression prevail.

Limitations

A well-known threat to the validity of meta-analysis is publication bias. Nonsignificant study outcomes are generally underreported in the literature. However, there are good reasons to assume that publication bias did not distort the present findings. Great lengths were taken to retrieve unpublished studies, resulting in a moderately large proportion (24\%) of effect sizes from unpublished data. The found trend towards a difference in effect size between unpublished and published studies could be explained by the exclusive use of questionnaires in unpublished studies. Moreover, most studies included in the meta-analysis did not primarily concern the correlation between reactive and proactive aggression, so their publication is unlikely to have depended on the magnitude of this correlation.

\section{Conclusion}

Reactive and proactive aggression can be distinguished clearly. Studies primarily focusing on the functions of proactive and reactive aggression (behavioral observations and disentangling questionnaires) most clearly demonstrate the distinctness of both constructs. Therefore, the distinction between both concepts is made most clearly when considering reactive and proactive aggression in terms of their function. Frequently used reactive and proactive aggression questionnaires were not originally designed to specifically assess the functions of aggressive behaviors independent of form. High correlations between reactive and proactive aggression found with these questionnaires may have resulted from this approach. Disentangling form and function may contribute to a better understanding of the relation between reactive and proactive aggression and the relations between forms and functions of aggressive behavior. It seems of much use to design empirical studies to evaluate the extent to which different measures and different informants are capable of distinguishing between reactive and proactive functions of different forms of aggression.

Acknowledgements This research was funded in part by Dutch Scientific Organization grant 453-03-110 to Bram Orobio de Castro. We acknowledge the practical aid and constructive advice of Laura Menenti and Joop Hox.

\section{References $^{3}$}

Achenbach, T. M., McConaughy, S. H., \& Howell, C. T. (1987). Child/adolescent behavioral and emotional problems: Implications of cross-informant correlations for situational specificity. Psychological Bulletin, 101, 213-232.

Allen, M., D’Alessio, D., \& Brezgel, K. (1995). A meta-analysis summarizing the effects of pornography II: Aggression after exposure. Human Communication Research, 22, 258-283.

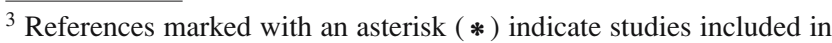
the meta-analysis.
} 
*Atkins, M. N. (1993). The relationship between reactive and proactive aggression in peer affiliations. Dissertation Abstracts International, 54, 4905B. (UMI No. 9403346).

*Atkins, M. N., McKay, M. M., Frazier, S. L., Jakobsons, L. J., Arvanitis, P., Cunningham, T., et al. (2002). Suspensions and detentions in an urban, low-income school: Punishment or reward? Journal of Abnormal Child Psychology, 30, 361-371.

*Atkins, M. S., Osborne, M. L., Bennett, D. S., Hess, L. E., \& Halperin, J. M. (2001). Children's competitive peer aggression during reward and punishment. Aggressive Behavior, 27, 1-13.

*Atkins, M. S., \& Stoff, D. M. (1993). Instrumental and hostile aggression in childhood disruptive behavior disorders. Journal of Abnormal Child Psychology, 21, 165-178.

Bandura, A. (1973). Aggression: A social learning analysis. Englewood Cliffs, NJ: Prentice-Hall.

*Boivin, M., Dodge, K. A., \& Coie, J. D. (1995). Individual-group behavioral similarity and peer status in experimental play groups of boys: The social misfit revisited. Journal of Personality and Social Psychology, 69, 269-279.

*Boivin, M., Vitaro, F., Hodges, E., \& Poulin, F. (1998). The quality of peer relationships and homophily in proactive and reactive aggression among preadolescent boys and girls. Paper presented at the International Society for the Study of Behavioural Development, Bern, Switzerland.

*Brendgen, M., Vitaro, F., Tremblay, R. E., \& Lavoie, F. (2001). Reactive and proactive aggression: Predictions to physical violence in different contexts and moderating effects of parental monitoring and care-giving behavior. Journal of Abnormal Child Psychology, 29, 293-304.

Brendgen, M., Vitaro, F., Boivin, M., Dionne, G., \& Perusse, D. (2006). Examining genetic and environmental effects on reactive versus proactive aggression. Developmental Psychology, 42, 1299-1312.

*Brown, K., Atkins, M. S., Osborne, M. L., \& Milnamow, M. (1996). A revised teacher rating scale for reactive and proactive aggression. Journal of Abnormal Child Psychology, 24, 473-480.

Bushman, B. J., \& Anderson, C. A. (2001). Is it time to pull the plug on the hostile versus instrumental dichotomy? Psychological Review, 108, 273-279.

*Camodeca, M., Goossens, F. A., Meerum Terwogt, M., \& Schuengel, C. (2002). Bullying and victimization among school-age children: Stability and links to proactive and reactive aggression. Social Development, 11, 332-345.

Card, N. A., \& Little, T. D. (2006). Proactive and reactive aggression in childhood and adolescence: A meta-analysis of differential relations with psychosocial adjustment. International Journal of Behavioral Development, 30, 446-480.

${ }^{*}$ Connor, D. F., Steingard, R. J., Anderson, J. J., \& Melloni, R. H. (2003). Gender differences in reactive and proactive aggression. Child Psychiatry and Human Development, 33, 279-294.

Crick, N. R. (1996). The role of overt aggression, relational aggression, and prosocial behavior in the prediction of children's future social adjustment. Child Development, 67, 2317-2327.

Crick, N. R., Casas, J. F., \& Mosher, M. (1997). Relational and overt aggression in preschool. Developmental Psychology, 33, $579-588$.

Crick, N. R., \& Dodge, K. A. (1996). Social information processing mechanisms in reactive and proactive aggression. Child Development, 67, 993-1002.

Crick, N. R., \& Grotpeter, J. K. (1995). Relational aggression, gender, and social psychological adjustment. Child Development, 66, 710722.

*Day, D. M., Bream, L. A., \& Pal, A. (1992). Proactive and reactive aggression: An analysis of subtypes based on teacher perceptions. Journal of Clinical Child Psychology, 21, 210-217.

Dodge, K. A. (1991). The structure and function of reactive and proactive aggression. In: D. J. Pepler \& K. H. Rubin (Eds.), The de- velopment and treatment of childhood aggression (pp. 201-218) Hillsdale, NJ: Erlbaum.

*Dodge, K. A., \& Coie, J. D. (1987). Social-information processing factors in reactive and proactive aggression in children's peer groups. Journal of Personality and Social Psychology, 53, 11461158.

Dodge, K. A., Lochman, J. E., Harnish, J. D., Bates, J. E., \& Pettit, G. S. (1997). Reactive and proactive aggression in school children and psychiatrically impaired chronically assaultive youth. Journal of Abnormal Psychology, 106, 37-51.

*Dodge, K. A., Price, J. M., Bachorowski, J. A., \& Newman, J. P. (1990). Hostile attributional biases in severely aggressive adolescents. Journal of Abnormal Psychology, 99, 385392.

Dollard, J., Doob, L. W., Miller, N. E., Mowrer, O. H., \& Sears, R. R. (1939). Frustration and aggression. New Haven, CT: Yale University Press.

Field, A. (1999). A bluffer's guide to meta-analysis 1. Newsletter of the Mathematical, Statistical and Computing section of the British Psychological Society, 7, 16-25.

${ }^{*}$ Frey, C., \& Hoppe-Graff, S. (1994). Serious and playful aggression in Brazilian girls and boys. Sex Roles, 30, 249-268.

${ }^{*}$ Goldstein, W. L. B. (1999). The relationship among the symptoms associated with $\mathrm{AD} / \mathrm{HD}$ subtypes and sociometric status among peers. Dissertation Abstracts International, 60, 3553B. (UMI No. 9940279).

Grotpeter, J. K., \& Crick, N. R. (1996). Relational aggression, overt aggression, and friendship. Child Development, 67, 23282338.

*Gurevich, L. A. (1996). Insecure attachment and deviant social information processing as mechanisms associated with violent behavior in adolescent offenders. Dissertation Abstracts International, 57, 6573B. (UMI NO. 9708574).

*Hegland, S. M., \& Rix, M. K. (1990). Aggression and assertiveness in kindergarten children differing in day care experiences. Early Childhood Research Quarterly, 5, 105-116.

*Hendrickx, M., Crombez, G., Roeyers, H., \& Orobio deCastro, B. (2003). Psychometrische evaluatie van de Nederlandstalige versie van de Agressie Beoordelingsschaal van Dodge en Coie (1987) [Psychometric evaluation of the Dutch version of Dodge \& Coie's (1987) aggression rating scale]. Tijdschrift voor Gedragstherapie, $36,33-43$.

*Hoving, K. L., Wallace, J. R., \& LaForme, G. (1979). Aggression during competition: Effects of age, gender, and amount and type of provocation. Genetic Psychology Monographs, 99, 251289.

*Hubbard, J. A., Smithmeyer, C. M., Ramsden, S. R., Parker, E. H., Flanagan, K. D., Dearing, K. F., et al. (2002). Observational, physiological, and self-report measures of children's anger: Relations to reactive versus proactive aggression. Child Development, 73 , 1101-1118.

*Kupersmidt, J., Willoughby, M. T., \& Bryant, D. (1998). Proactive and reactive aggression in preschool children. Paper presented at the Biennial Meeting of the International Society for the Study of Behavioural Development, Bern, Switzerland.

Lansford, J. E., Dodge, K. A., Bates, J. E., \& Pettit, G. S. (2002). Developmental trajectories of reactive and proactive aggression: Similarities and differences over time. Paper presented at the $\mathrm{XVth}$ world meeting of the International Society for Research on Aggression, Montreal, Canada.

Lipsey, M. W., \& Wilson, D. B. (2001). Practical meta-analysis. Thousand Oaks, CA: Sage.

Little, T. D., Brauner, J., Jones, S. M., Nock, M. K., \& Hawley, P. H. (2003). Rethinking aggression: A typological examination of the functions of aggression. Merril Palmer Quarterly, 49, 343369. 
*Little, T. D., Jones, S. M., Henrich, C. C., \& Hawley, P. H. (2003). Disentangling the "whys" from the "whats" of aggressive behaviour. International Journal of Behavioral Development, 27, 122-133.

Lochman, J. E., \& Dodge, K. A. (1998). Distorted perceptions in dyadic interactions of aggressive and nonaggressive boys: Effects of prior expectations, context, and boys' age. Development and Psychopathology, 10, 495-512.

*van Manen, T. G., Prins, P. J., \& Emmelkamp, P. M. G. (2001). Assessing social cognitive skills in aggressive children from a developmental perspective: The social cognitive skills test. Clinical Psychology and Psychotherapy, 8, 341-351.

* Marcus, R. F., \& Kramer, C. (2001). Reactive and proactive aggression: Attachment and social competence predictors. Journal of Genetic Psychology, 162, 260-276.

McAdams III, C. R. (2002). Trends in the occurrence of reactive and proactive aggression among children and adolescents: Implications for preparation and practice in child and youth care. Child and Youth Care Forum, 31, 89-109.

*Merk, W., Orobio deCastro, B., Koops, W., \& Matthys, W. (2004). Concurrent and predictive relations of reactive and proactive aggression. Paper presented at the XVIIIth meeting of the International Society for the Study of Behavioural Development, Ghent, Belgium.

Merk, W., Orobio deCastro, B., Koops, W., \& Matthys, W. (2005). The distinction between reactive and proactive aggression: Utility for theory, diagnosis and treatment? European Journal of Developmental Psychology, 2, 197-220.

*Miller-Johnson, S., Coie, J. D., Maumary-Gremaud, A., \& Bierman, K. (2002). Peer rejection and aggression and early starter models of conduct disorder. Journal of Abnormal Child Psychology, 30, 217-230.

Nisbett, R. E., \& DeCamp Wilson, T. (1977). Telling more than we can know: Verbal reports on mental processes. Psychological Review, 84, 231-259.

Orobio de Castro, B., Brendgen, M., Van Boxtel, H., Vitaro, F., \& Schaepers, L. (2007). "Accept me or else ..." Overestimation of own social competence predicts increases in proactive aggression. Journal of Abnormal Child Psychology, doi.org/10.1007/s10802006-9063-6

Orobio de Castro, B., Merk, W., Koops, W., Veerman, J. W., \& Bosch, J. D. (2005). Emotions in social information processing and their relations with reactive and proactive aggression in referred aggressive boys. Journal of Clinical Child and Adolescent Psychology, 34, 105-116.

Ostrov, J. M., \& Crick, N. R. (in press). Forms and functions of aggression during early childhood: A short-term longitudinal study. School Psychology Review.

Orwin, R. G. (1994). Evaluating coding decisions. In: H. Cooper \& L. V. Hedges (Eds.), The handbook of research synthesis. New York: Sage.

Pakaslahti, L., \& Keltikangas-Jaervinen, L. (2000). Comparison of peer, teacher and self-assessment on adolescent direct and indirect aggression. Educational Psychology, 20, 177-190.

*Phillips, N. C., \& Lochman, J. E. (2003). Experimentally manipulated changes in children's proactive and reactive aggressive behavior. Aggressive Behavior, 29, 215-227.

${ }^{*}$ Poulin, F., \& Boivin, M. (2000a). Reactive and proactive aggression: evidence of a two-factor model. Psychological Assessment, 12, $115-122$.

*Poulin, F., \& Boivin, M. (2000b). The role of proactive and reactive aggression in the formation and development of boys' friendships. Developmental Psychology, 36, 233-240.

*Price, J. M., \& Dodge, K. A. (1989). Reactive and proactive aggression in childhood: Relations to peer status and social context dimensions. Journal of Abnormal Child Psychology, 17, 455471.
*Prinstein, M. J., \& Cillessen, A. H. N. (2003). Forms and functions of adolescent peer aggression associated with high levels of peer status. Merril Palmer Quarterly, 49, 310-342.

*Raine, A., Dodge, K. A., Loeber, R., Gatzke-Kopp, L., Lynam, D., Reynolds, C., et al. (2006). The reactive-proactive questionnaire: differential correlates of reactive and proactive aggression in adolescent boys. Aggressive Behavior, 32, 159-171.

*Ramsden, S. R., \& Hubbard, J. A. (2002). Family expressiveness and parental emotion coaching: their role in children's emotion regulation and aggression. Journal of Abnormal Child Psychology, 30, 657-667.

*Roland, E., \& Idsøe, T. (2001). Aggression and bullying. Aggressive Behavior, 27, 446-462.

Saal, F. E., Downey, R. G., \& Lahey, M. A. (1980). Rating the ratings: Assessing the psychometric quality of rating data. Psychological Bulletin, 88, 413-428.

*Salmivalli, C., \& Nieminen, E. (2002). Proactive and reactive aggression among school bullies, victims, and bully-victims. Aggressive Behavior, 28, 30-44.

*Scarpa, A., Hurley, J. D., \& Hirai, M. (2002). Emotional and behavioral correlates of reactive and proactive aggression in children. Paper presented at the XVth world meeting of the International Society for Research on Aggression, Montreal, Canada.

*Schippell, P. L. (2001). The role of narcissism self-esteem and attentional biases in childhood reactive and proactive aggression. Dissertation Abstracts International, 62, 2077B (UMI No. AAI3011142)

*Schippell, P. L., \& Vasey, M. W. (2003). Suppressed attention to rejection, ridicule, and failure cues: A unique correlate of reactive but not proactive aggression in youth. Journal of Clinical Child and Adolescent Psychology, 32, 40-55.

* Schwartz, D. (1994). The social behavior of bullied children. Dissertation Abstracts International, 55, 5087B (UMI No. 9510793).

Schwartz, D., Dodge, K. A., Coie, J. D., Hubbard, J. A., Cillessen, A. H. N., Lemerise, E. A., et al. (1998). Social-cognitive and behavioral correlates of aggression and victimization in boys' play groups. Journal of Abnormal Child Psychology, 26, 431440.

*Smithmyer, C. M., Hubbard, J. A., \& Simons, R. F. (2000). Proactive and reactive aggression in delinquent adolescents: Relations to aggression outcome expectancies. Journal of Clinical Child Psychology, 29, 86-93.

Solley, S. R. (1995). Subtypes of aggression in childhood disruptive behavior disorders. Dissertation Abstracts International, 56, 3464B. (UMI No. 9535807).

*Steffens, H. (1999). Kindspecifieke diagnostiek en behandeling van agressief gedrag [Individual assessment and treatment of aggressive behavior]. Unpublished master's thesis, University of Amsterdam.

*Strassberg, Z., Dodge, K. A., Pettit, G. S., \& Bates, J. E. (1994). Spanking in the home and children's subsequent aggression toward kindergarten peers. Development and Psychopathology, 6, 445461.

*Vazzana, A. D. (2001). Outcome expectations and outcome values of proactive, reactive, and nonaggressive boys. Dissertation $A b$ stracts International, 62, 2506B. (UMI No. 3013806).

Vitaro, F., Brendgen, M., \& Barker, E. D. (2006). Subtypes of aggressive behaviors: A developmental perspective. International Journal of Behavioral Development, 30, 12-19.

*Vitaro, F., Brendgen, M., \& Tremblay, R. E. (2002). Reactively and proactively aggressive children: Antecedent and subsequent characteristics. Journal of Child Psychology and Psychiatry, 43, 495505 .

Vitaro, F., Gendreau, P. L., Tremblay, R. E., \& Oligny, P. (1998). Reactive and proactive aggression differentially predict later conduct 
problems. Journal of Clinical Child Psychology and Psychiatry, 39, 377-385.

*Waschbusch, D. A., Willoughby, M. T., \& Pelham, W. E. (1998). Criterion validity and the utility of reactive and proactive aggression: Comparisons to attention deficit hyperactivity disorder, oppositional defiant disorder, conduct disorder, and other measures of functioning. Journal of Clinical Child Psychology, 27, 396405.

Wilson, S. J., \& Lipsey, M. W. (2000). Wilderness challenge programs for delinquent youth: A meta-analysis of outcome evaluations. Evaluation and Program Planning, 23, 112 